\title{
BMJ Open Primary care for people with severe mental illness and comorbid obstructive airways disease: a qualitative study of patient perspectives with integrated stakeholder feedback
}

\author{
Caroline Mitchell (1) , ${ }^{1}$ Nicholas Zuraw, ${ }^{1}$ Brigitte Delaney, ${ }^{1}$ Helen Twohig, ${ }^{2}$ \\ Neil Dolan, ${ }^{1}$ Elizabeth Walton, ${ }^{1}$ Joe Hulin, ${ }^{3}$ Camelia Yousefpour ${ }^{4}$
}

To cite: Mitchell C, Zuraw N, Delaney B, et al. Primary care for people with severe mental illness and comorbid obstructive airways disease: a qualitative study of patient perspectives with integrated stakeholder feedback. BMJ Open 2022;12:e057143. doi:10.1136/ bmjopen-2021-057143

- Prepublication history and additional supplemental material for this paper are available online. To view these files, please visit the journal online (http://dx.doi.org/10.1136/ bmjopen-2021-057143)

Received 07 September 2021 Accepted 10 February 2022

Check for updates

(C) Author(s) (or their employer(s)) 2022. Re-use permitted under CC BY-NC. No commercial re-use. See rights and permissions. Published by BMJ.

For numbered affiliations see end of article.

Correspondence to

Dr Caroline Mitchell;

c.mitchell@sheffield.ac.uk

\section{ABSTRACT}

Objectives To explore patient and stakeholder perspectives on primary respiratory care for people with severe mental illness (SMI) and comorbid obstructive airways disease (OAD).

Design Qualitative, semistructured qualitative interviews were undertaken with a purposive sample of people with a diagnosis of SMI (bipolar illness, schizophrenia, affective disorder with psychosis) and comorbid asthma or chronic obstructive pulmonary disease. Transcribed data were analysed using an interpretive phenomenological approach. Study results were discussed with stakeholders. Setting Eight UK general practices.

Participants 16 people aged $45-75$ years, with SMI and comorbid asthma or chronic obstructive pulmonary disease, were interviewed. Twenty-one people, four with lived experience of SMI and seventeen health/social care/ third sector practitioners, participated in discussion groups at a stakeholder event.

Results Participants described disability and isolation arising from the interplay of SMI and OAD symptoms.

Social support determined ease of access to primary care. Self-management of respiratory health was not personcentred as practitioners failed to consider individual needs and health literacy. Participants perceived smoking cessation impossible without tailored support. Less than half of the practices facilitated personalised access to timely primary care and continuity. Overall, there was a reliance on urgent care if service adaptations and social support were lacking. The stakeholder group expressed concern about gaps in care, the short-term funding of community organisations and fear of loss of benefits. Potential solutions focused on supported navigation of care pathways, relational continuity, individual and community asset building and the evolving social prescriber role. Conclusion This study suggests that despite UK guidelines and incentives to optimise physical healthcare, primary care fails to consistently deliver integrated biopsychosocial care for patients with SMI and OAD. Collaborative, personalised care that builds social capital and tailors support for self-management is needed, alongside service-level interventions to enhance access to healthcare for patients with comorbid SMI and OAD.
Strengths and limitations of this study

- The purposive sampling strategy across multiple practices provides a rich idiographic exploration of the experiences of care by a diverse patient group.

- Public, patients and practitioners were involved at all stages of the research process, including synthesis of research findings and recommendations for further research and service redesign.

- Our sample was not ethnically diverse, which may reflect cultural barriers to discussion of mental health outside of confidential healthcare settings and a lack of interpreter support for non-English speakers.

- The general practices were in urban settings in South Yorkshire (UK) and healthcare may differ elsewhere.

\section{BACKGROUND}

People living with a severe mental illness (SMI), defined as schizophrenia, bipolar disease or affective disorder with psychosis, have a life expectancy reduced by an average of 20 years and a higher prevalence of physical comorbidities compared with the general population. ${ }^{1-3}$ This population experiences inequitable access to routine healthcare, demonstrates an overreliance on urgent care and also faces barriers to self-management of physical comorbidities. ${ }^{4-6}$ Diagnostic overshadowing by the SMI may contribute to poor physical health outcomes. ${ }^{7}$

Chronic obstructive pulmonary disease (COPD) and asthma are the two most common non-communicable chronic lung diseases globally. ${ }^{8}$ A link between SMI and obstructive airways disease (OAD) is partially explained by higher rates of smoking tobacco and/or cannabis, but socioeconomic deprivation and other environmental factors may 
also be relevant. ${ }^{9}$ A systematic review of over 200 observational studies identified that patients with schizophrenia or bipolar disorder were more likely to suffer from comorbid COPD with an OR of 1.573 and 1.551 , respectively. ${ }^{10}$ In their observational study, Burke et al identified high rates of COPD on spirometry for inpatients with SMI, half of whom did not have an OAD diagnosis at the time suggesting a hidden burden of respiratory disease. ${ }^{11}$ Hospitalisation rates for COPD and adult asthma exacerbations are higher in patients with comorbid SMI, even once adjusted for other pre-existing health conditions, socioeconomic factors and demographics. ${ }^{12}$

Primary care interventions shown to improve health outcomes for OAD include medicines optimisation, vaccinations, non-pharmacological interventions, which enable supported self-management such as personalised care plans and aids to stop smoking and in addition for COPD, pulmonary rehabilitation. ${ }^{13-15}$ Timely access to respiratory care is important. It enables early diagnosis and treatment, improves long-term outcomes and reduces unscheduled care and hospitalisations for exacerbations of both asthma and COPD in the general population. ${ }^{16-18}$ In a large UK primary care study, healthcare factors including influenza vaccination and access to primary care consultations were protective against hospital admission rates for people with COPD. ${ }^{19}$

Despite their higher burden of OAD, there is little research about the experience of respiratory care for people with comorbid SMI. This contrasts with a large evidence base used to support cardio-metabolic assessment and enhanced cardiometabolic care in SMI. ${ }^{20-23}$

This study aims to:

- Explore the perspectives of people living with SMI and $\mathrm{OAD}$ on their experience of respiratory healthcare in the primary care setting.

- Integrate stakeholder feedback to identify potential interventions to improve respiratory healthcare.

\section{METHODS}

Design

A qualitative interpretive phenomenological study.

\section{Data collection}

People with SMI and OAD were interviewed using a semistructured format. A literature review and consultation with two patient and public involvement (PPI) groups informed the interview topic guide and recruitment approach (online supplemental appendix 1). We approached a diverse range of general practices including some in the most socioeconomically deprived areas of South Yorkshire, UK.

General practice staff undertook computer database searches, using standardised Systematized Nomenclature of Medicine Clinical Terms (SNOMED) coding and the UK Quality and Outcome Framework (QOF) criteria to identify eligible participants. ${ }^{2425}$

Inclusion criteria were patients on the practice QOF 'Mental Health' Register (patients aged 18 years and over with schizophrenia, bipolar affective disorder and other psychoses) with comorbid asthma or COPD. Exclusion criteria included palliative patients, those with cognitive impairment associated with dementia or severe learning disability and those receiving care under the Mental Health Act.

We posted a study pack to eligible participants. This included a consent form, an information sheet, a reply slip addressed directly to the study team and a prepaid envelope.

Participants who returned the reply slip were contacted to arrange the interview in their home or at the university. The content of the information sheet as well any other queries participants had were discussed at the start of the interview. If a participant consented to participate, (s) he signed the consent form and the interview began.

Interviews with 16 participants from eight practices in South Yorkshire were carried out by trained qualitative interviewers in participants' homes or at the university. The interviews lasted between $25 \mathrm{~min}$ and $75 \mathrm{~min}$, but the majority lasted $45 \mathrm{~min}$ or more. Researchers wrote field notes straight after each interview to support reflexivity and for discussion within debriefing and analysis meetings. Interviews were audio-recorded and transcribed verbatim. We asked about sociodemographic characteristics in each interview, calculated the index of multiple deprivation by postcode and allocated standardised categories to a previous occupation to preserve participant anonymity. ${ }^{26}{ }^{27}$ Pseudonyms are assigned to each quote and cross-referenced to a table summarising sociodemographic characteristics (table 1).

\section{Analysis}

An inductive interpretive phenomenological analytical approach (IPA) was used to explore the participants' lived experience of the dual diagnoses of OAD and SMI and experiences of respiratory healthcare. ${ }^{28}$ IPA is particularly suitable for a case-based approach and has a dual focus on the unique characteristics of individuals and the patterning of meaning.

Transcripts were read initially while listening to the audio-recording and reread by the researchers to familiarise themselves with participants' accounts and document exploratory coding (NZ and ND). Anonymised data were organised and analysed using NVivo software (V.12) and emergent themes were linked to coded data. Interviews continued until data saturation and a purposive sample had been achieved using a case-by-case approach to data analysis and multiple practice sampling. ${ }^{29}$ Coding was independently verified by sequential analysis of all transcripts (CM and $\mathrm{BD})$ and the thematic framework generated was subjected to critical interpretive challenge within the whole team. Reflexivity and interdisciplinary perspectives were key to the self-conscious analysis process (COREQ research checklist).

We presented the results in lay format at a public stakeholder event, to which people with lived experience of SMI, mental health third sector workers, commissioners, 


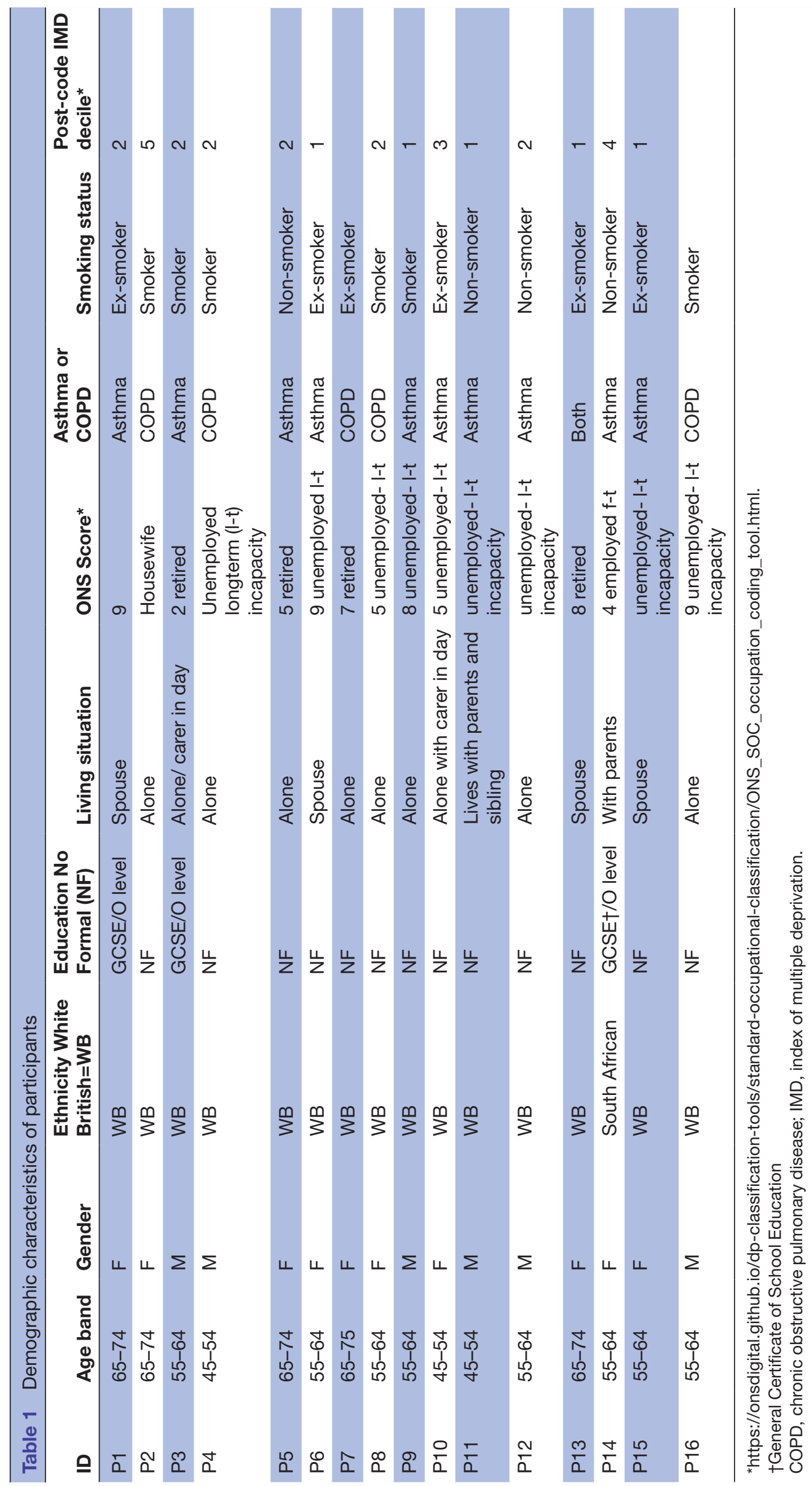

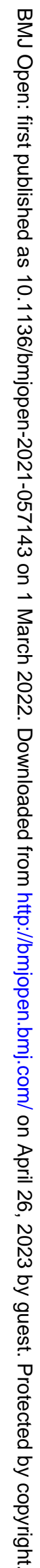


health and social care trust managers and health and social care practitioners were invited. This allowed others with lived experiences of SMI to comment on findings. ${ }^{28}$ The research team then facilitated three stakeholder discussion groups to explore potential interventions to improve access to care for long-term respiratory health problems for people with SMI.

\section{Patient and Public Involvement}

This research arose from clinical observations and feedback from patients about experiences of respiratory healthcare for people with SMI and comorbid OAD. We presented the initial research ideas and consulted with two PPI groups. The first PPI group (Sun:Rise) is a PPI group comprised of people with lived experience of mental illness. Several of the members of the Sun:Rise group also had comorbid physical health problems. The second PPI group is a group of patients and public living in the communities served by the 'Deep End Sheffield' cluster research network (DES CRN) of practices who provide feedback and input to research conducted within their practices.

These consultations informed the development of an interview topic guide, project documentation and approaches to recruitment. When the study was completed, we presented the results back to both PPI groups and provided a lay summary of the results for wider dissemination. We have acknowledged the contribution of these PPI groups and also the DES CRN practitioners in shaping the research process with the team.

A stakeholder event was convened for people with lived experience of SMI (from the Sun:Rise PPI group) and multidisciplinary/multisector representatives to discuss findings and potential next steps for intervention development and service redesign. A visual scribe observed and recorded accessible outputs contemporaneously for the stakeholders and wider dissemination (online supplemental appendix 2).

\section{RESULTS}

The sociodemographic characteristics of the participants are summarised in table 1 . Of the participants aged 45 to 75 years old, nine were women and seven were men. Ten participants had comorbid asthma, six participants had COPD. In two of the interviews, a family carer was present at the request of the participant and contributed to the interview. Fifteen participants were no longer under follow-up by a community mental health team. One patient was receiving care for COPD from a hospital clinic. Ten participants lived alone and almost all lived in areas of significant socioeconomic deprivation. The majority of participants were current smokers $(6 / 16)$ or ex-smokers $(6 / 16)$. Most participants had left school with no formal qualifications $(12 / 15)$ and were unemployed or had retired.

Data saturation was achieved in three main themes: 'Social support', 'Self-management challenges' and 'Service accessibility'. Table 2 summarises the main themes, explanatory subthemes and further illustrative quotes.

\section{Social support}

A person's social support influenced access to care. The term social support incorporates living within supportive families and communities, financial and material resources, formal or informal carer support. Deficient support arose from social isolation and exclusion from families and the wider community, which were in turn influenced by poverty, unemployment, poor access to transport, the burden of SMI symptoms and impact of historical trauma (including child abuse, domestic violence) on family structures.

\section{Support networks}

Social networks enabled participants to navigate and negotiate access to healthcare. Examples of support and advocacy included accompanying participants to appointments and neighbours or family calling for help during illness exacerbations.

Jack retired through ill health. He lives alone and has asthma in addition to SMI. He described collaborative continuity of health and social care and a supportive social network, which enabled him to feel less fearful about being ill and alone.

\section{It's like I've got (name of carer), I've got a couple of other friends, you know, that if I'm feeling, you know, like, at night time, they'd rally round. She's a trained social worker, but she doesn't work for social services, ... and she's con- nected with the doctors, she works with the National Health, so that was the difference. She was compassionate. Jack P3 aged 54-64 years}

Paul had been unemployed following a long period of ill health and has COPD in addition to his SMI. He lives alone. A friend now monitored his health and well-being.

We're the same age. Known each other years, like. We get on and he'll phone up every now and again 'are you alright', because he'll see if my lights on and off, because otherwise I'll go to bed, I'll stop in bed two days. Paul P4 aged 45-54 years

\section{Social isolation}

The majority of participants lived alone. Participants reported social isolation arising from the disabling dual burden of SMI and OAD, compounded by living in poverty and a lack of access to transport and / or social networks to overcome that isolation.

Neil lives alone, is unemployed and described increasing disability from deteriorating mental and physical health. His lack of close family or friends left him feeling vulnerable and fearful about maintaining his independence and being seriously ill and alone.

At the end, what's going to happen? Am I going to be able to keep my flat or is this going to get worse so am I'm unable to look after myself? I don't think it will... I think it'll come 
Table 2 Summary of themes and subthemes

Sub-

\section{Key themes themes Additional quotes}

Social Support ....because I've got a good support network. It's like I've got (name of lay carer), I've got a couple of support networks other friends, you know, that if I'm feeling, you know, like, at night time, they'd rally round. P3 I've got family close by so that's why I moved here.... I go to them...Because if they keep coming to see me, I'll not want to go out and that's why l'll not go out. So, I went yesterday afternoon to see her and I've got another sister up there. P9

I'm more assertive and, like, 'this is why we've come to see you, this is what the issue is' and whatever, so it's being directed - Daughter of $\boldsymbol{P} 7$

Social When I'm really ill, I can't leave the house, I can't leave my bedroom, I can't go anywhere, I can't isolation do anything. So yeah, then I avoid it and then sometimes I might get a doctor to get come out here or just to tweak my medication over the phone and then my parents go and pick up some more medication for me or something like that. P14.

but the thing with tablets, you see, you go on tablets for your nerves and I'd experienced it I mean, I didn't talk to people for over ten years hardly, after my son died, I was on nerve tablets and I never spoke, I was a complete introvert, people couldn't communicate... I had no life, I had no joy in my life, I had no spirit, you know what I mean? - $\boldsymbol{P} 2$

Self Health management literacy challenges
I'm not very clever, so I went round the corner for the day and I used to - went to learn to read and write. I can read a bit still, not well, but I don't go now because they stopped it. And I used to enjoy going there. so it used to get me out of the house. P10

Because then when I go to hospital to see a doctor to talk medical terms and to me it's like jig-saw and its pieces are missing I think. P15

Before the last visit, I didn't realise I was using my reliever more often than I should have done. Now they've changed it to an all in one, the reliever and the other one P12

Interplay Expense and physical difficulties travelling to review appointments and getting out of house of poverty Because I have to get a taxi to go then I get a taxi back. - P 9 and I'm currently DLA (Disabled Living allowance) but I've just been to a face to face interview for disability changing over to Personal Independence Payment...I've never worked. P12

Smoking I'm going on my own situation and some people I do know - when you've got mental health problems, it's like because you're deep in thought or you're trying to achieve something or you're not trying to achieve something or escape, you can't control your emotions, your feelings, your tensions and a cigarette sort of stops you from shouting at somebody, you know?... I've tried stopping smoking again and I can't do it... P 2

I prefer to smoke.... Because I've nowt else in my life but smoking...I've always been told what to do and what not to do and smoking's something I choose to do on my own. P 8

\begin{tabular}{|c|c|c|}
\hline $\begin{array}{l}\text { Service } \\
\text { accessibility }\end{array}$ & $\begin{array}{l}\text { Continuity } \\
\text { of care }\end{array}$ & $\begin{array}{l}\text { I mean, the doctors have changed because they've retired, but I've got a really good young GP, } \\
\text { they call her Dr X. - P } 5 \\
\text { Dr Y's very understanding, he'll start the conversation off first and I find it - my other doctor, Dr M, I } \\
\text { found it right easy talking to him - P } 8 \\
\text { It seems they don't really talk to each other about what's coming up or look on the screen, just see } \\
\text { the words on the screen rather than the patient themselves, the whole person. P12 }\end{array}$ \\
\hline & Urgent care & $\begin{array}{l}\text { I don't know, so Asthma, if I get like all bit restless about Asthma and that kicks off like a bit of a } \\
\text { panic attack and then that's sort of where the Bipolar comes in. When I get into that kind of a state } \\
\text { I don't know which one comes first. But I just know that when I do get breathless it's exceptionally } \\
\text { breathless and we have to phone for an ambulance P14 } \\
\text { Since January, so that's in the last sixteen weeks, we've had an ambulance out four times. She's } \\
\text { been nebulised and left at home twice and she's been admitted twice to have her oxygen levels } \\
\text { monitored, so they put her on oxygen and both times it was because of an onset of an infection } \\
\text { which made things worse. Daughter of P } 10 \\
\text { When I was really ill my husband phoned the doctor and he sort of came not long after and I got m) } \\
\text { care straight away. They got me nurses and that together, you know, that dealt with this and they } \\
\text { were really positive. - P } \mathbf{1}\end{array}$ \\
\hline & $\begin{array}{l}\text { Navigating } \\
\text { complex } \\
\text { care } \\
\text { pathways }\end{array}$ & $\begin{array}{l}\text { With mental health, there's nothing, there's only my doctor, I feel sorry for him because I know } \\
\text { that - because when I go down to see him, there's loads of my kind what's already there waiting } \\
\text { to see him too who suffer with mental illness. He's not just dealing as a doctor, he's also dealing } \\
\text { as a psychiatrist and as a nurse and everything all in one and if you're in a right tizwas, he's got to } \\
\text { try and calm you down. And same if you've got asthma problems, he helps me with that too, you } \\
\text { know, he's always checking. I don't get a chance to sit down with him and that because he's alway } \\
\text { on the rush with me, you know, checking that I'm alright. I'm very grateful...P12 }\end{array}$ \\
\hline
\end{tabular}


to the point where I have to go in some kind of supported housing just so I've got... like if anything happened to me at night nobody would know. Neil P16 aged 55-64 years

Breathlessness and anxiety about leaving the house were often interrelated and acted as barrier to access to healthcare. Janet in addition to asthma and SMI has other physical comorbidities, which restrict her mobility. Although relatively young, she is unemployed and mostly housebound with both formal and family carer support.

(Carer) And that's when P's stress thresholds rise through the ceiling and of course then, for some reason, it aggravates asthma. When P's stressed, her asthma's worse. Janet P10 aged 55-64 years

Patients, especially those with COPD, described a trajectory towards an isolated, housebound existence.

I get stressed out sort of thing. I spend most of my life in here now, where you wouldn't get me in the house at one bit. Paul P4

\section{Self-management challenges}

Supported self-management interventions outside of general practice such as 'stop smoking' support, pharmacy-based interventions (eg, medicines review including inhaler technique) and pulmonary rehabilitation were poorly accessed, if at all. None of the participants could recall discussion of shared written asthma or COPD care plans with practitioners to help them recognise and safely self-manage exacerbations. Participants used medication to relieve symptoms and sought urgent unscheduled care when they felt ill. These unplanned episodes of care predominated in the interviews rather than a picture of supported proactive self-management.

\section{Lack of health literacy}

The majority of participants had left school without any formal qualifications. All our participants had English as a first language but health literacy was identified as an issue in both written communication and in healthcare consultations.

Janice left school without any formal qualifications, had been unemployed for many years and lives with her husband.

Sometimes they'll send you a letter.... and I think 'what does that say, what does that say?... We can read, but I can't read and write properly Janice P15 age 55-64 years

Neil described the use of inaccessible jargon and overcomplicated explanations in consultations:

Sometimes, yeah. And then sometimes you think well you might as well be speaking in a foreign language because I don't understand anything. If you come out with... if people use big terms, big medical terms, I don't understand, no. Speak so I can understand it. Neil P16 age 55-64 years, no formal qualifications
None of the participants had accessed written or online self-management support materials. Derek needed help to fill in forms from his support worker:

Yeah, she (community support worker) does it for asthma as well, so she helps me with the form filling to ease my anxiety, because I sometimes get confused with certain words that's on the pages. Derek P12 age 55-64 years

\section{The interplay of poverty and disability}

Poverty compounded disability and both factors impaired access to healthcare. Participants were reliant on 'good (health) days', public transport and carers (formal, friends and family) to get out of their home. Perhaps consequently, participants frequently described how they were forced to restrict their use of precious personal and social resources to support access to healthcare.

Patrick has been unemployed for many years. He described how disabling mental health and physical symptoms sapped motivation to self-care and access healthcare.

I can't be bothered to do 'owt...As you can see, I haven't hoovered up yet. Patrick P9 age 55-64 years, lives alone, asthma

Over time, the use of home services such as pharmacy deliveries acted as a lifeline to medication but also reflected increasing isolation and the accelerated trajectory to housebound status.

Because it costs me $£ 10$ to go there, to the chemist and back, because there isn't a direct bus...I can't walk up the hill because I get really breathless. Joan P5 age 65-74 years, lives alone, asthma

\section{Smoking}

The majority of participants were current or ex-smokers. For those who were smokers, smoking was embedded within daily routines and used habitually to self-manage 'stress' as Tina describes:

Perhaps more than other people but smoking, people used smoking for a lot of things and it can cause - it can take stress away. Tina $\mathrm{P} 2$ age $65-74$ years, COPD

Despite a desire to stop and attempts to quit in many instances, smoking cessation, a cornerstone of self-management of risk of disease progression and exacerbations, was perceived as an impossible goal. Community-based smoking cessation support did not meet the needs of participants, as there was no specific psychological support offered for alternative strategies to manage distressing mental health symptoms.

I was smoking as many on patches as when I weren't on patches. Patrick P9 age 55-64 years, COPD

There were also fears that some smoking cessation medications could make mental health worse

No good for me, but I've got high stress levels so I've tried patches, they just burn me and itch. I've tried them things, 
they just hurt my throat. And I can't take them tablets what they can prescribe because I go suicidal on them. Paul P4 aged 45-54 years, COPD

\section{Service accessibility}

Social support and advocacy by formal and informal carers alongside service adaptations (or lack of them) strongly influenced access to care. Most of the participants found it difficult to single handedly navigate fragmented healthcare services for both SMI and OAD. However, examples of responsive, good primary care were also shared.

\section{Continuity of care}

Trust, perceived and received stigma and complex disability influenced confidence in accessing primary care and consultations in unfamiliar settings and with unfamiliar practitioners.

They really class it (mental illness) as a taboo subject and, you know, that you must be of a lower class and whatever. Tina P2

I'm really comfortable with her, the others, I don't know, so I'm not comfortable... [I] Tend to hold back...I just don't tell them everything like I should....It's like if I don't know them, I don't trust them, but with the doctor I go and see, I trust her completely. Debra P7 age 65-74 years, COPD

Relational continuity with local healthcare practitioners helped counteract geographical and psychological barriers to healthcare. Participants consistently expressed a preference for continuity of care, but this was not always available in their practices.

Because it just seems too much hard work to get in and then when you go you're not seeing the same doctor. If it were the same doctor who were dealing with my COPD I'd be a lot happier. Neil P16

Seeing an unfamiliar nurse provoked this response from Derek :

It seems they don't really talk to each other about what's coming up or look on the screen, just see the words on the screen rather than the patient themselves, the whole person. Derek P12

Several participants commented on the impact of a lack of a health or social care worker to support access to care. This advocacy role had been addressed historically by 'keyworkers' within mental health teams.

Shortness of breath, I didn't know what it was, I'd pushed myself and not having anybody to confide in really,...I think if I'd had like a key worker to help me or someone who I could trust in, I perhaps would have got the diagnosis before that and had more help. Tina P2

Joan described how she knew the practice staff well, experienced good continuity of care and perhaps consequently was more confident in seeking timely care:
I've got a good relationship with my GP and the nurses and the receptionists. They're absolutely brilliant. If I hadn't got that network, I wouldn't be here. I would have been gone. I would have took my own life. Joan P5

\section{Use of urgent care}

Normalisation of poor physical health, a failure to access timely primary care, a lack of self-management skills and little social support meant that patients often waited until they were very unwell before seeking help from their precarious social network to support access to urgent healthcare.

I'm like ... you know shortish breaths and I can't breathe because I ain't got my inhalers and that. But, luckily, I've got an old lass downstairs, she's like a mother I should have had! She's $84 \ldots$ she always checks up on me, phones me up every day. Paul $\mathrm{P} 4$

One patient described repeated visits to accident and emergency department with atypical chest pain before the diagnosis of asthma was made.

It just came on suddenly. I'd been going to A E'E with chest pains originally and they suggested that as I didn't have any issues with my heart, to have asthma, you know, tested at the doctors .... And it was. And since I've been on the medication, the symptoms of the chest pain have gone. I got diagnosed! Joan P5

Debra preferred to avoid attending her general practice unless her COPD deteriorated and relied on her daughter to book her appointments.

If I'm not very well I have to go to the doctors, I tell my daughter and she'll make an appointment and takes me to the doctors, but I try not to go too much, I try and stop in the house. I stop in the house a lot. Debra P7

Some participants gave positive feedback about continuity of care and familiarity with the practice systems, which enabled timely urgent primary care.

I know at any time I can phone up and if my chest's bad I can guarantee that she'll fit me in in the next couple of days. Jack P3

\section{Navigating complex care pathways}

Participants described fragmented mental and physical healthcare across primary and secondary services, with specialist and disciplinary silos leading to extra appointments with scant evidence of integrated care.

I was a bit disappointed. I went in one day with a bad chest and it was for a mental health check and it was a psychiatrist and she was very nice, but I was annoyed because they didn't tell me that. I went because I thought it was for my chest because I wanted some help. And she listened to my chest and she said 'oh it's a bit rough but you'll be better in two months' time, it'll be completely alright' and I thought that was strange saying that. Tina P2 (has COPD). 
With the nurse, physical health comes first. Doctor, mental health comes first. Debra P7

Overlapping and frequent appointments from different services were needed to address care needs for multiple complex health problems.

But sometimes I can't get there because I've got appointments with the hospital. But hospital, she likes me to be there so I cancel that and I say 'can you make me another one. Neil $\mathrm{P} 16$

A carer described her difficulties in supporting the complex needs of the patient and to also negotiate timely access to appropriate care:

...this happens quite frequently because she is really bad at the asthma, I rang up and they said 'can you fetch her in', I've complained since, that's not easy, she has mobility problems, so P's had operations on both feet, she's got pins in her toes, she's got arthritis in her joints, in her knees, in her hips and also in her shoulders and she lives on the first floor, so when a doctor says 'can you bring her in', that's not always easy. Janet $\mathrm{P} 10$

\section{Stakeholder discussion groups}

The results were presented in lay format at a public stakeholder event, to which four people with lived experience of SMI, mental health charity workers, primary care commissioners, health and social care trust managers and clinicians (a social prescriber, a General Practitioner, practice and mental health nurses) were invited. A total of 21 stakeholders participated in the three discussion groups.

The public stakeholder group expressed similar concerns about gaps in care and, in addition, fear of loss of benefits and the short-term funding of community organisations. Potential solutions focused on adequate resources, supported navigation of care pathways, relational continuity, individual and community asset building and the evolving integrated social prescriber role.

Stakeholders supported service redesign to mandate inclusive access to healthcare, recognising the challenges facing those with an SMI in the navigation of complex appointment systems for multiple mental and physical health problems.

A tailored 'social prescribing' intervention was felt by stakeholders to have potential to enhance selfmanagement skills and social networks of people with comorbid SMI and OAD and other long-term physical health conditions. A visual summary of the discussion was provided for the stakeholder members at the end of the meeting and used to further disseminate study findings to local practitioners (online supplemental appendix 2).

\section{DISCUSSION}

In our study, participants described extraordinary disability and isolation arising from the interplay of SMI and OAD symptoms. Social support determined ease of access to primary care. There were challenges in selfmanagement of respiratory health, in particular, a lack of personalised asthma or COPD care plans and a failure of some practitioners to consider individual needs and health literacy. However, there was a reliance on urgent care if service adaptations and social support were lacking.

Social support encompasses living within supportive families and communities, financial and material resources. ${ }^{30}$ In our study, a lack of personal resources and social support contributed to a downward spiral in social contacts and activities outside the home. In a qualitative meta-synthesis of lived experience of mental-physical multimorbidity, Coventry et al describe how the experience of multimorbidity is: 'underscored by a sense in which bodies had become broken, had begun to fall apart and grind to a halt, leading to much more circumscribed and less rewarding lives'. Social support was characterised as a 'buffer' against the stresses of living with multimorbidity, a finding which resonated with the experiences of the participants in our study. ${ }^{31}$

In our study, participants also described how psychological and practical support provided by a social network could enable the person to adapt and cope with the work of chronic illness and negotiate access to healthcare. ${ }^{32}$ The term social support overlaps with the complex construct of 'social capital' and people living with SMI are disadvantaged compared with the general population. ${ }^{33} 34$ A more recent systematic review was unable to reach clear conclusions about the effects of social capital on access to healthcare, limited primarily by inconsistencies in how social capital and healthcare access were conceptualised and measured. ${ }^{35}$ Nonetheless, our stakeholder group suggested that building social support and addressing poverty and other structural influences on social isolation might enhance access to care. A social asset-based approach (building community and individual resources) may have potential to alter the restrictive housebound trajectory for those with SMI and comorbid OAD and support positive change in health-related behaviours. ${ }^{35}$ The advent of 'Social Prescribing' initiatives in primary care could support the unmet physical and psychosocial needs identified in our study and support condition selfmanagement and timely access to primary care. ${ }^{36} 37$

The complex interplay of social, mental and physical challenges experienced by our participants contributed to normalisation of poor physical health. Ill-health was experienced as a series of 'crises' with increased use of urgent rather than timely primary or self-care previously described in relation to people with mental-physical multimorbidity. ${ }^{4-6}{ }^{19}$ Our study illustrates the shared characteristics of people with an SMI with other vulnerable patient groups included in a synthesis of evidence concerning 'Vulnerable Patients and access to healthcare' (Dixon et al).$^{38}$ Two key constructs which mediate access to care relevant to our theme Service accessibility' are relevant; 'Candidacy' and 'Permeability' of healthcare organisations (figure 1). In our study, 'candidacy', the 


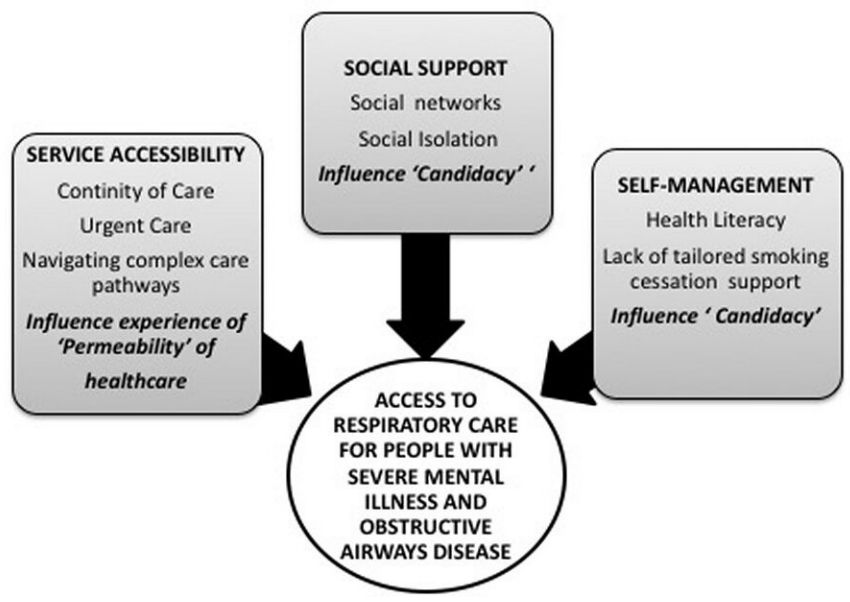

Figure 1 Access to care for people with severe mental Illness and co-morbid obstructive airways disease: a thematic framework incorporating 'candidacy' and 'permeability' constructs derived from 'Vulnerable groups and Access to Care' Dixon et al. ${ }^{38}$ Definitions: candidacy describes the ways in which people's eligibility for medical attention and intervention is jointly negotiated between individuals and health services'. 'Permeability-Services can be conceptualised in terms of how porous and permeable they are. High permeability services are those are most confortable for people to use that demand the fewest qualifications for candidacy, and that require less work. Services that are less permeable require much more work in order to gain a point of entry and sustain engagement with service'.

ways in which people's eligibility for medical care is negotiated jointly between patients and health services, was mediated by informal and family care and practitioner relational continuity. Lay carers and in some instances GP receptionists advocated for the person and thereby enabled access to care.

The construct of 'Permeability' describes how much work and engagement with the healthcare service is needed to gain access to care. ${ }^{38}$ Our study describes a wide range of contextual primary care experiences from holistic healthcare with continuity, to depersonalised and fragmented care. There is a need to reconsider how to implement the collaborative biopsychosocial person-centred approach to physical and mental healthcare in primary care advocated by Lester and others for people with mental-physical multimorbidity. ${ }^{39-41}$ This could include incentives and other policy-driven initiatives, in line with disability legislation, to address inequitable access to healthcare for people with mental-physical multimorbidity. ${ }^{41-44}$

\section{CONCLUSION}

There is a need to increase awareness of the impact of comorbid OAD in people with SMI. The provision of personalised, collaborative health and social care for this group, which prioritises relational continuity by practitioners, builds individual social capital, tailors support for self-management and addresses barriers in access to primary care appointments is warranted. Further research should focus on the development and evaluation of integrated personalised health and social care interventions for people with comorbid SMI and OAD, which consider social connectedness as an important influence on access to care.

\section{Author affiliations}

${ }^{1}$ Academic Unit of Primary Medical Care, The University of Sheffield, Sheffield, UK ${ }^{2}$ Institute for Primary Health Care and Health Sciences, Keele University, Keele, Staffordshire, UK

${ }^{3}$ Mental Health, Research Unit, Sheffield School of Health and Related Research, University of Sheffield, Sheffield, UK

${ }^{4}$ Academic Unit of Primary Medical Care, The University of Sheffield Faculty of Medicine Dentistry and Health, Sheffield, UK

\section{Twitter Caroline Mitchell @dclovesGP}

Acknowledgements Grant funded by the Clare Wand Fund (BMA). The research was also part-funded by the NIHR CLAHRC Yorkshire and Humber. www.clahrc-yh. nihr.ac.uk. The views expressed are those of the author(s), and not necessarily those of the NIHR or the Department of Health and Social Care. A 'SURE'

Scholarship from the University of Sheffield funded N Dolan to undertake a summer research internship. Helen Twohig is a Wellcome Trust Primary Care Doctoral Fellow (2017-2021) at Keele University. Elizabeth Walton NIHR Clinical Lecturer 20152020. Patient and public involvement: SUN:RISE patient and public involvement group(PPI), Sheffield Health and Social Care NHSFT; the Deep End Yorkshire and Humber NIHR Clinical Research Network Cluster Patient and Practitioner group. We thank Chris Rhymes, lead research nurse, NIHR Clinical Research Network Yorkshire and Humber; Dr Michelle Horsepool (PhD) Deputy Director -Research, Sheffield Health and Social Care NHSFT and NHS Sheffield CCG; Dr Kirsty Payne, Foundation Doctor, Laura Evans from Nifty Fox Creatives.

Contributors $\mathrm{CM}$ is the responsible for the overall content and is guarantor for the work. All authors have fulfilled the four ICMJE criteria for authorship. Original conception and design and writing of the study protocol (CM, JH, HT, EW, BD). Ethical approvals (CM, BD, NW). Acquisition of the data (BD, NW, ND, CM, EW), analysis and interpretation of the data (all authors). Drafting the work (all authors). Final Approval of the version to be published (all authors). Agreement to be accountable for all aspects to the work (all authors). Integrated stakeholder and PPIE work by CM, NZ, ND, BD.

Funding Grant funded by the Clare Wand Fund (BMA). The research was also partfunded by the NIHR CLAHRC Yorkshire and Humber. www.clahrc-yh.nihr.ac.uk.

Competing interests None declared.

Patient consent for publication Not applicable.

Ethics approval This study involves human participants and was approved by South Central-Hampshire B Research Ethics Committee approved this study Reference/ethics ID number 17/SC/0353. Participants gave informed consent to participate in the study before taking part.https://www.hra.nhs.uk/ planning-and-improving-research/application-summaries/research-summaries/ access-to-treatment-for-long-term-lung-disease-in-people-with-a-smi/

Provenance and peer review Not commissioned; externally peer reviewed.

Data availability statement № data are available. This a qualitative database and to protect anonymity of the participants, the data is not available publically, even in an anonymised complete format. Reasonable requests to discuss explanatory quotes with the lead researcher may be made.

Supplemental material This content has been supplied by the author(s). It has not been vetted by BMJ Publishing Group Limited (BMJ) and may not have been peer-reviewed. Any opinions or recommendations discussed are solely those of the author(s) and are not endorsed by BMJ. BMJ disclaims all liability and responsibility arising from any reliance placed on the content. Where the content includes any translated material, BMJ does not warrant the accuracy and reliability of the translations (including but not limited to local regulations, clinical guidelines, terminology, drug names and drug dosages), and is not responsible for any error and/or omissions arising from translation and adaptation or otherwise.

Open access This is an open access article distributed in accordance with the Creative Commons Attribution Non Commercial (CC BY-NC 4.0) license, which permits others to distribute, remix, adapt, build upon this work non-commercially, 
and license their derivative works on different terms, provided the original work is properly cited, appropriate credit is given, any changes made indicated, and the use is non-commercial. See: http://creativecommons.org/licenses/by-nc/4.0/.

\section{ORCID iD}

Caroline Mitchell http://orcid.org/0000-0002-4790-0095

\section{REFERENCES}

1 Liu NH, Daumit GL, Dua T, et al. Excess mortality in persons with severe mental disorders: a multilevel intervention framework and priorities for clinical practice, policy and research agendas. World Psychiatry 2017:16:30-40.

2 Barnett K, Mercer SW, Norbury M, et al. Epidemiology of multimorbidity and implications for health care, research, and medical education: a cross-sectional study. Lancet 2012;380:37-43.

3 Razzano LA, Cook JA, Yost C, et al. Factors associated with cooccurring medical conditions among adults with serious mental disorders. Schizophr Res 2015;161:458-64.

4 DE Hert M, Correll CU, Bobes J, et al. Physical illness in patients with severe mental disorders. I. prevalence, impact of medications and disparities in health care. World Psychiatry 2011;10:52-77.

5 Public Health England. Severe mental illness (SMI) and physical health inequalities: briefing. Research and Analysis, 2018. Available: https://www.gov.uk/government/publications/severe-mental-illnesssmi-physical-health-inequalities/severe-mental-illness-and-physicalhealth-inequalities-briefing

6 Lawrence D, Kisely S. Inequalities in healthcare provision for people with severe mental illness. J Psychopharmacol 2010;24:61-8.

7 Jones S, Howard L, Thornicroft G. 'Diagnostic overshadowing': worse physical health care for people with mental illness. Acta Psychiatr Scand 2008;118:169-71.

8 Viegi G, Maio S, Fasola S, et al. Global burden of chronic respiratory diseases. J Aerosol Med Pulm Drug Deliv 2020;33:171-7.

9 Reilly S, Olier I, Planner C, et al. Inequalities in physical comorbidity: a longitudinal comparative cohort study of people with severe mental illness in the UK. BMJ Open 2015;5:e009010.

10 Zareifopoulos N, Bellou A, Spiropoulou A, et al. Prevalence of comorbid chronic obstructive pulmonary disease in individuals suffering from schizophrenia and bipolar disorder: a systematic review. COPD 2018;15:612-20.

11 Burke AJ, Hay K, Chadwick A, et al. High rates of respiratory symptoms and airway disease in mental health inpatients in a tertiary centre. Intern Med J 2018;48:433-8.

12 Davydow DS, Ribe AR, Pedersen HS, et al. Serious mental illness and risk for hospitalizations and rehospitalizations for ambulatory care-sensitive conditions in Denmark: a nationwide population-based cohort study. Med Care 2016;54:90-7.

13 National Institute for Health and Care Excellence. Chronic obstructive pulmonary disease in over 16s: diagnosis and management. Pract Nurse 2018;48 www.nice.org.uk/guidance/ng115

14 Scottish Intercollegiate Guidelines Network, British Thoracic Society. SIGN 158: British guideline on the management of asthma [online], 2019. Available: https://www.brit-thoracic.org.uk/qualityimprovement/guidelines/asthma/

15 Global Initative for Chronic Obstructive Lung Disease (GOLD). Global strategy for the diagnosis, management, and prevention of chronic obstructive pulmonary disease 2018 report [online], 2018. Available: http://www.goldcopd.org/uploads/users/files/GOLD_Report_2015 Apr2.pdf

16 Snell N, Strachan D, Hubbard R. S32 Epidemiology of chronic obstructive pulmonary disease (COPD) in the uk: findings from the british lung foundation's 'respiratory health of the nation' project. Thorax 2016;71.

17 NHS England. A resource to support commissioners in setting a level of ambition on reducing premature mortality Prepared by Medical Directorate [online], 2014. Available: https://www.england.nhs.uk/wpcontent/uploads/2014/02/rm-fs-6.pdf

18 Royal College of Physicians. Why asthma still kills - The National Review of Asthma Deaths (NRAD) confidential enquiry report [online], 2014. Available: https://www.rcplondon.ac.uk/projects/outputs/whyasthma-still-kills

19 Calderón-Larrañaga A, Carney L, Soljak M, et al. Association of population and primary healthcare factors with hospital admission rates for chronic obstructive pulmonary disease in England: National cross-sectional study. Thorax 2011;66:191-6.
20 Primary Care Strategy and NHS Contracts Group. 2019/20 general medical services (GMS) contract quality and outcomes framework (QOF), 2019. Available: https://www.england.nhs.uk/wp-content/ uploads/2019/05/gms-contract-qof-guidance-april-2019.pdf

21 NHS England. Improving physical healthcare for people living with severe mental illness (SMI) in primary care guidance for CCGs, 2018. Available: https://www.england.nhs.uk/wp-content/uploads/ 2018/02/improving-physical-health-care-for-smi-in-primary-care. pdf

22 Kronenberg C, Doran T, Goddard M, et al. Identifying primary care quality indicators for people with serious mental illness: a systematic review. Br J Gen Pract 2017;67:e519-30.

23 Lester H, Shiers D, Rafi I, et al. Positive cardiometabolic health resource [online], 2014. Available: https://www.rcpsych.ac.uk/docs/ default-source/improving-care/ccqi/national-clinical-audits/ncaplibrary/ncap-e-version-nice-endorsed-lester-uk-adaptation.pdf? sfvrsn=39bab4 2

24 SNOMED CT in electronic care: records. Available: https://www. england.nhs.uk/digitaltechnology/digital-primary-care/snomed-ct/

25 Primary Care Strategy and NHS Contracts Group. 2019/20 genera medical services (GMS) contract quality and outcomes framework (QOF), 2019. Available: https://www.england.nhs.uk/wp-content/ uploads/2019/05/gms-contract-qof-guidance-april-2019.pd

26 Ministry of Housing, Communities \& Local Government. English indices of deprivation, 2019. Available: https://imd-by-postcode. opendatacommunities.org/imd/2019

27 Office for National Statistics. Occupational classification (SOC). Available: https://www.ons.gov.uk/methodology/classificationsandst andards/standardoccupationalclassificationsoc

28 Smith JA, Flowers P, Larkin M. Interpretative phenomenological analysis: theory, method and research. 5th edn. Sage, 2009.

29 Patton MQ. Sampling, qualitative (purposive). The Blackwell encyclopedia of sociology 2015.

30 Keeley B. Human capital. How what you know shapes your life, 2007: 102-10. https://www.oecd.org/insights/humancapitalhoww hatyouknowshapesyourlife.htm

31 Coventry PA, Small N, Panagioti M, et al. Living with complexity; marshalling resources: a systematic review and qualitative metasynthesis of lived experience of mental and physical multimorbidity. BMC Fam Pract 2015;16:171.

32 Corbin J, Strauss A. Managing chronic illness at home: three lines of work. Qual Sociol 1985;8:224-47.

33 Chronister J, Chou C-C, Kwan K-LK, et al. The meaning of social support for persons with serious mental illness. Rehabil Psychol 2015;60:232-45

34 McKenzie K, Whitley R, Weich S. Social capital and mental health. $\mathrm{Br}$ J Psych 2002;181:280-3.

35 Derose KP, Varda DM. Social capital and health care access: a systematic review. Med Care Res Rev 2009;66:272-306.

36 Brandling J, House W. Social prescribing in general practice: adding meaning to medicine. Br J Gen Pract 2009;59:454-6.

37 Payne K, Walton E, Burton C. Steps to benefit from social prescription: a qualitative interview study. $\mathrm{Br} J$ Gen Pract 2020;70:e36-44.

38 Dixon M, Ms W, DK M, et al. Vulnerable groups and access to health care: a critical interpretive review Report for the National Coordinating Centre for NHS Service Delivery and Organisation R \& D (NCCSDO). England NH, 2005.

39 NHS England, Coalition for Collaborative Care. Personalised care and support planning handbook: the journey to person-centred care. Available: https://www.nhs.uk/NHSEngland/keogh-review/ Documents/pers-care-guid-core-guid.pdf

40 Lester H. Shared care for people with mental illness: a GP's perspective. Adv Psych Treat 2005;11:133-9.

41 Rijken M, Struckmann V, Heide vander. ICARE4EU Consortium. How to improve care for people with multimorbidity in Europe?. World Health Organization, Regional, 2019. Available: https://www.euro. who.int/_data/assets/pdf_file/0004/337585/PB_23.pdf

42 Roland M, Guthrie B. Quality and outcomes framework: what have we learnt? BMJ 2016;354:i4060

43 et alNaylor C, Das P, Ross S. Bringing together physical and mental health, 2016. Available: https://www.kingsfund.org.uk/sites/default/ files/field/field_publication_file/Bringing-together-Kings-Fund-March2016 1.pdf

44 De Maeseneer J, Boeckxstaens P. James MacKenzie lecture 2011: multimorbidity, goal-oriented care, and equity. $\mathrm{Br} J$ Gen Pract 2012;62:e522-4 https://bjgp.org/content/62/600/e522.short 